\title{
EDUCATION, POVERTY AND THE TRAP OF POOR COUNTRIES IN THE FACE OF DEVELOPMENT
}

Carlos Alberto Jiménez Bandala ${ }^{\bowtie}$, Luis Antonio Andrade ${ }^{2}$

\author{
${ }^{凶 1}$ Facultad de Negocios Universidad La Salle México, México, carlos_jimenez@ulsa.mx \\ ${ }^{2}$ Facultad de Negocios, Universidad La Salle México, México
}

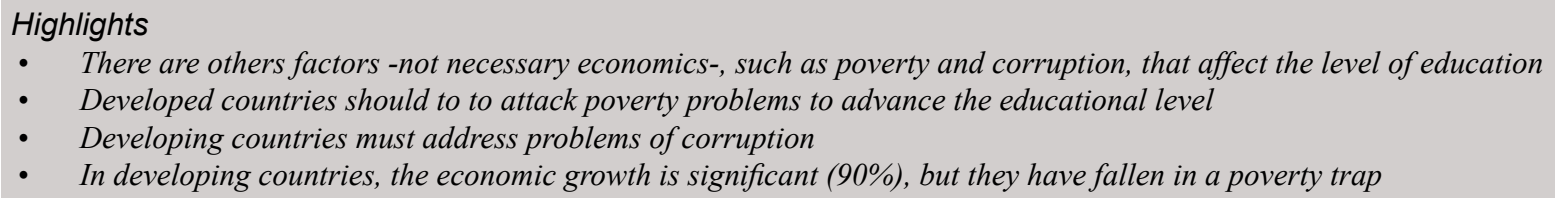

\section{Abstract}

This article aims to identify the level of incidence of social and economic variables on education, considering the existence of a cumulative circular causation, in order to point out public policy recommendations to improve people's well-being and thus increase Indicators of development, especially in educational matters. An econometric analysis integrates available information from 128 countries between the period 2010-2015. The results show different effects on the level of incidence of social and economic variables between rich and poor countries.

\section{Keywords}

Cumulative Circular Causation, development, econometrics, literacy, poverty trap
Article type

Full research paper

Article history

Received: July 4, 2017

Received in revised form: October 27, 2017

Accepted: October 27, 2017

Available on-line: December 20, 2017

Jiménez Bandala C.A., Andrade L.A. (2017) "Education, Poverty and The Trap of Poor Countries in The Face of Development", Journal on Efficiency and Responsibility in Education and Science, Vol. 10, No. 4, pp. 101-108, online ISSN 1803-1617, printed ISSN 2336-2375, doi: 10.7160/eriesj.2017.100402.

\section{Introduction}

The World Bank was founded in 1944 with one principal goal: reducing poverty. The World Bank adopted two specific objectives in 2015: 1) to end extreme poverty and 2) to promote shared prosperity. The World Bank hopes to reduce a share of people living in extreme poverty to $3 \%$ by 2030 . Moreover, another goal is to increase an income of the poorest by $40 \%$ (World Bank, 2016). The strategies for achieving these two goals are to promote growth that is sustainable and inclusive, to create more and better jobs, to invest in people's health, education, nutrition, and sanitation (World Bank, 2017a). Therefore, education is seen as a powerful tool to end poverty. According to data from the World Bank (2016), in the last 50 years, poverty has declined significantly. However, there are still two notable problems: a) poverty reduction has been uneven on the planet. Eastern European countries have reduced poverty more rapidly, whereas other countries in Africa and Latin America have had many difficulties to fight the poverty. b) Higher poverty is harder to eradicate. People living with USD 3.10 per day decreased from 2.59 billion in 1981 to 2.2 billion in 2011 (barely 390 million people less, which is approximately $15 \%$ less over a period of 30 years). This stagnation shows the vulnerability of people to an eventual return of poverty. Therefore, the progress could be temporary and in the face of any contingency such as "economic shocks, food insecurity and climate change threaten to rob them of their hard-won gains and force them back into poverty" (World Bank, 2017b: 2).

On the other hand, education has been seen as a powerful tool to eradicate poverty. If we consider illiteracy figures, we can observe that adults who do not know how to read or write decreased from 871 million in 1980 to 758 million in 2014 (UNESCO, 1995; UNESCO, 2014). A reduction of just over
100 million, which equals to a reduction ofless than $13 \%$ in 34 years. As in poverty reduction, we seem to be stuck. If the behaviors were linear it would take about 200 years to eradicate poverty and 250 years to eradicate illiteracy. However, the world economic arose by $114 \%$ in the same period (IMF, 2017). It seems that economic growth has no relation to the reduction of both poverty and illiteracy, at least its effects have been small. Our research problem then arises. Why is poverty persistent? Why is illiteracy persistent too? Is it possible that poverty may be eradicated through education? Or indeed, illiteracy will be eradicated when poverty ends? In this paper, we investigate the relationship between poverty and education.In this sense, the article aims to identify the level of incidence of social and economic variables on education. We consider that many countries are in a trap, as they cannot get out of either a poverty or illiteracy. There is a small effect of economy on education. Therefore, we argue that the social conditions are the major factors for improving education.

The literature over the relation of education with other economic and social factors, with an econometric analysis, is wide. For example, Bonilla (2013) uses average years of schooling as a proxy for human capital. Arellano and Bond's (1991) methodology shows that the total of average years of schooling, as well as the level of structural development and investment effort of a country, are significant in order to explain the rate of an economic growth. Others authors (Barro, 1991; Romer, 1986) show that the human capital in education is significant for the economic growth.

The article is organized as follows: In the first section, we continue with an extension of the introduction in a relation how to understand the the education, as well aswith an explication of 
Cumulative Circular Causation and poverty trap. In the second section, we introduce the methodology of our research, as well as the dataset. In section three, we present the obtained results with an emphasis to a decomposition between rich and poor, followed by their respective econometric analysis. Finally, in section 4 we focus on some concluding remarks and discussion.

\section{Education, independent or dependent variable?}

Education is an exclusively human characteristic that separates us from the rest of the hominids, and allows to transmit knowledge, skills and abilities. However, at the same time, the education frames cultural patterns, axiological norms, rules and practices of life in society (Bruner, 1997). Thus, education is the instrument by which productive forces and means of production are produced through the scientific and technological development. This promotes both qualitative and quantitative advances of the mode of production. What is more, education is an instrument by which a society is reproduced socially through their ideals, values and habits too.

Education is a seed of transformative and, therefore, liberating thought (Freire, 1970), as it contributes to the fact that, at a certain level of development, means of production and productive forces to be contradicted each other and overcoming becomes revolutions through which humanity advances. Here arises the importance of the role of education in social development.

According to UNESCO (1958), an individual is illiterate if: "cannot with understanding both read and write a short simple statement on his [or her] everyday life" (UNESCO, 1958: 3). Reading and writing were defined as the minimum capacities that a human being should have. It is about the most basic educational conditions and from which we follow in this study. The lag in literacy leads a country to continuous lags in subsequent levels of education (Sauvageot, 1978; UNESCO, 2006). Thus, it is essential to take care of illiteracy as a priority for nations.

In the 1950s, in the context of a growing debate over developmental theories, education, particularly measured by illiteracy rates, became an indicator of the degree of a country development (Cipolla, 1969; UNESCO, 1957). This means that education is the result of economic growth, because "growth" and "development" were seen as a binomial. On the other hand, some more authors began considering education as the indispensable prerequisite of a country for economic take-off (Rostow, 1960). This other view recognizes education as the cause. The question here is about the role of the relationship education and economic growth, whether education is the independent or dependent variable?

International policies that have been developed after the $1980 \mathrm{~s}$ and 1990s overlapped idea that education is an independent variable. Therefore, national governments and international agencies should focus their efforts on increasing literacy to boost economic growth and development. Even boosting education is one of the strategies the World Bank has set to achieve its goal of eradicating extreme poverty by 2030 (World Bank, 2016).

In 1995 UNESCO presented that the developed countries increased their literacy rate more rapidly than the least developed countries. In fact, during the period from 1980 to 1995 , the illiterate population decreased by 16 million in developed countries, whereas in developing countries the illiteracy increased by 24 million people (UNESCO, 1995). It seems that there is a logical relationship between poverty and education, which could explain that the persistence of poverty in developing countries lies in the persistence of illiteracy. Hence, despite the public policies implemented throughout the 1980s, why was illiteracy persistent in 1995 ? What is more, This persistency is currently in force.

\section{Cumulative Circular Causation and poverty trap}

Myrdal (1957) argues that particularly countries and poor regions face a problem of "Cumulative Circular Causation" in which the effects of a cause of underdevelopment trigger other causes that accumulate cyclically, widening the gaps of poverty. As a result, development is not in a balanced way. From this perspective, the effects at one point become causes at another time. That is, independent variables become dependent and vice versa:

"When the system starts rolling it is 'true that the changes in the forces' - though not all the forces themselves - work in one direction; but it is because the variable are assumed to be interlocked in such a causal mechanism that a change of any one causes the others to change in the same direction. With a secondary effect upon the first variable." (Myrdal, 1944: 1067)

For example, a country with a high poverty level (independent variable) will not be able to spend substantial expenditure on education as opposed to rich countries. So, its result will indicate a low educational level (dependent variable). However, at a later stage, the low level of education (independent variable) will consequently be the cause of a low level of scientific and technological development, and poor level of formation of fixed capital and industrial activities, and will be less attractive for foreign investment. As a result, this country will have a low growth of the Gross Domestic Product and, consequently, will continue with high level of poverty (dependent variable).

What we rescue from this approach is not only the ability to analyze the problem by investing the explained and explanatory variables, but also: a) to break with the cause-effect dichotomy and consider a factorial plurality that allows to include variables formerly considered exogenous or even externalities; b) moving from static schemes such as "vicious circles" (Nurkse, 1953) to speak of cycles with a cumulative tendency; c) amplify the action lines of public policy to address different problems, allowing to direct efforts to economic and social areas simultaneously or identifying the greatest effect in solving a problem.

Following Myrdal (1944), we consider that poverty and illiteracy are part of a cycle of cumulative causation that has not been addressed in an integral way. Because of expecting effects in one variable (poverty), all efforts have been focused on another variable (education). However, given a plurality of factors, other variables that were originally triggered have been neglected affecting the stagnation, for example corruption. Therefore, the poorest countries fall into a poverty trap that they cannot get out of, even by allocating more resources to what they consider as an independent variable, since, in the words of Myrdal (1944: 77), "a rational policy is unlikely to operate to achieve the change of a single factor".

\section{Materials and Methods}

According to the previous part, our variables for constructing the econometric model are as following:

- $\quad Y$ - Education;

- $X_{1}-$ Economic growth;

- $\quad X_{2}$ - Corruption level;

- $X_{3}$ - Homicides rate;

- $X_{4}$ - Unemployment rate;

- $X_{5}-$ Poverty rate.

In case of education, we consider the percentage of illiterate people, as reported by the World Bank statistics, which comes mainly from the census data of each country. Although there 
is an evidence that such indirect evaluation could overestimate literacy (UNESCO, 2006), we stay with it as it is the only comparable basis between countries.

Economic growth is based on the average real growth rate of the Gross Domestic Product of each country for the period 20102015 (IMF, 2017). The level of corruption is in relation to the Corruption Perception Index (CPI) developed by Transparency International (Transparency International, 2016). The values of CPI range from 0 to 100 , where 100 means the lowest possible level of corruption, and vice versa. The level of corruption is related to the year 2015 (Transparency International, 2016). For the homicide rate, we consider the proportion of homicides per 10,000 inhabitants, by the year 2015 (World Bank, 2017a). For the unemployment rate, data of an average of this rate is used for the period 2010-2015 (IMF, 2017). Last but not least. for the poverty rate, we take the percentage of people living on less than USD 1.9 a day (extreme poverty line) by 2015 (World Bank, 2017a). The sample size contains of 128 countries worldwide, which is the number of countries that reported complete information for all variables required during the period of study, as this was our criterion of selection.

Once all the variables were defined, we need to construct a functional form that would reflect the effect of the economic levels represented by the variable of economic growth. Economic growth would first softly impacted the level of education for low growth levels and, depending if the level of growth was increasing, so did the level of education (Figure 1)

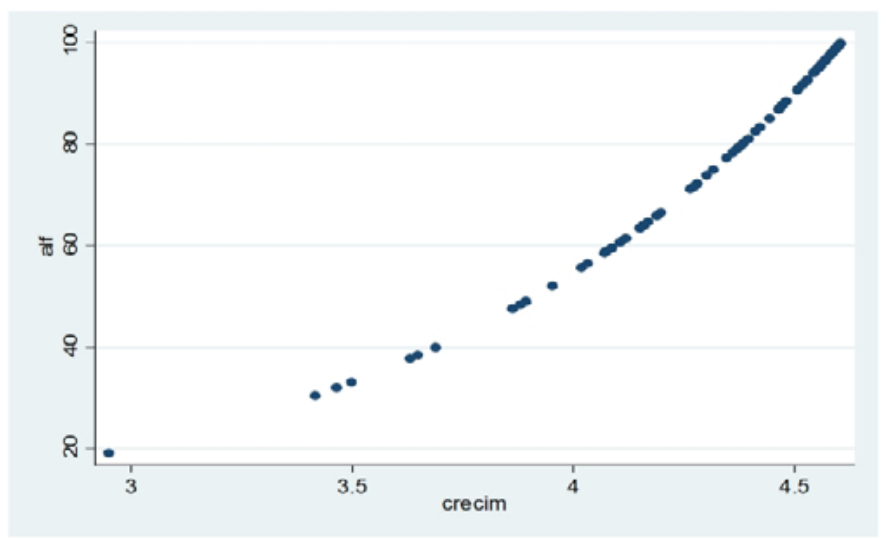

Figure 1: Relationship with decreasing returns between growth (axis $\mathrm{X}$ ) and education (axis Y) (source: own elaboration).

That is, we argue that the economic level would gradually affect the level of education. Thus, we proposed functional forms such as,

$$
\text { 1) } \begin{array}{r}
Y_{i}=\beta_{0}+\beta_{1} \ln X_{1 i}+\text { Some }+u_{i}, \\
Y_{i}=\beta_{0}+\beta_{1} \sqrt{X_{1 i}}+\text { Some }+u_{i} \\
Y_{i}=\beta_{0}+\beta_{1} e^{X_{1 i}}+\text { Some }+u_{i} \\
Y_{i}=\beta_{0}+\beta_{1} X_{1 i}{ }^{2}+\text { Some }+u_{i}
\end{array}
$$

In principle, proposals 1) and 2) are not feasible, since there are countries whose levels of growth are negative and, therefore, the expressions are not defined. Then, we work with the expressions (3) and (4), where the term relative to "Some" refers to the plurality proposed by Myrdal (1944). We consider factors such as corruption $\left(X_{2}\right)$, violence $\left(X_{3}\right)$, unemployment $\left(X_{4}\right)$ and poverty $\left(X_{5}\right)$. All as part of a cumulative circular causation process.

\section{Results}

In this section, we present our results regarding the aim of the article to identify the level of incidence of social and economic variables on education. First, we did the estimation with all the variables, because the majority of variables are of social character. Thus, our general model is as follows

$$
\begin{aligned}
Y_{i}=\beta_{0} & +\beta_{1} e^{X_{1 i}}+\beta_{2} X_{2 i}+\beta_{3} X_{3 i}+ \\
& +\beta_{4} X_{4 i}+\beta_{5} X_{5 i}+u_{i}
\end{aligned}
$$

We get the following result

$$
\begin{gathered}
\widehat{Y}_{i}=79.46592+2.49 \times 10^{-12} e^{X_{1 i}}+.2064117 X_{2 i}+ \\
+.1299047 X_{3 i}+.2569594 X_{4 i}-1.015 X_{5 i} \\
t=\begin{array}{llll}
(0.04)(4.28) & (0.117) & (1.22) \quad(-6.64), \\
R^{2}=0.4567
\end{array}
\end{gathered}
$$

The first estimation shows that corruption $\left(X_{2}\right)$ and poverty $\left(X_{5}\right)$ were the only significant variables. The growth factor, (taken as $e^{X_{1 i}}$ ), was not significant.

Subsequently, we made the following estimation,

$$
\begin{aligned}
Y_{i}=\beta_{0} & +\beta_{1} X_{1 i}^{2}+\beta_{2} X_{2 i}+\beta_{3} X_{3 i}+ \\
& +\beta_{4} X_{4 i}+\beta_{5} X_{5 i}+u_{i}
\end{aligned}
$$

With this second estimation, we get the following result,

$$
\begin{gathered}
\hat{Y}_{i}=79.46592-0.01588 X_{1 i}^{2}+.20571 X_{2 i}+ \\
+.122818 X_{3 i}+.2449 X_{4 i}-1.0103 X_{5 i} \\
t=\left(\begin{array}{lllll}
-0.90) & (4.31) & (1.05) & (1.17) & (-6.62), \\
0.4603 &
\end{array}\right.
\end{gathered}
$$

Similarly, as in estimation (1), corruption and poverty remain significant, whereas the other variables, including economic growth, remain non-significant. However, regarding Myrdal (1957), we wanted to keep the impact of the growth together with the only significant variables, corruption and poverty. So, we proposed the following two models, in which we treat the economic growth similarly as in (1) and (2):

$$
Y_{i}=\beta_{0}+\beta_{1} e^{X_{1 i}}+\beta_{2} X_{2 i}+\beta_{5} X_{5 i}+u_{i}
$$

and

$$
Y_{i}=\beta_{0}+\beta_{1} X_{1 i}^{2}+\beta_{2} X_{2 i}+\beta_{5} X_{5 i}+u_{i}
$$

The respective estimations for (3) and (4) are

$$
\begin{gathered}
\widehat{Y}_{i}=86.647-0.0000000083 e^{X_{1 i}}+ \\
+0.1857 X_{2 i}-1.033 X_{5 i} \\
t=(-0.03)(4.01) \quad(-6.76), \\
R^{2}=0.4448
\end{gathered}
$$


and,

$$
\begin{gathered}
\widehat{Y}_{i}=84.0841-0.0183 X_{1 i}{ }^{2}+0.1857 X_{2 i}-1.02 X_{5 i} \\
t=\quad(-1.04) \quad(4.06) \quad(-6.74), \\
R^{2}=0.4497
\end{gathered}
$$

Despite that the economic growth $\left(X_{1}\right)$ remains non-significant, an improvement is observed both statistically and intuitively in (4). It is important to note that the effects of the corruption and the poverty are almost the same in (3) and (4), i.e. they remain unchanged. To make the statement clearer, we did the following estimation,

$$
Y_{i}=\beta_{0}+\beta_{1} X_{1 i}+\beta_{2} X_{2 i}+\beta_{5} X_{5 i}+u_{i}
$$

Whose result was,

$$
\begin{gathered}
\widehat{Y}_{i}=83.8572-0.073 X_{1 i}+0.1859 X_{2 i}-1.033 X_{5 i} \\
t=\quad(-0.24) \quad(4.05) \quad(-6.76), \\
R^{2}=0.4451
\end{gathered}
$$

Similarly, as in the previous estimations, the economic growth remains unaffected. However, the socials variables, corruption and poverty, remain almost unchanged statistically and intuitively. The result are the following:

Theorem: In reference to Myrdal (1957) in the Cumulative Circular Causation process, the growth effect is no longer significant for the education, whereas exogenous variables previously considered as corruption and poverty become more important. Concluding that, even by modifying the size of the impact of growth, the effects of social variables on education are invariant under any permitted functional and logical form of economic growth.

Despite the non-significance of the growth over education. It is worth rescuing expression (4), that shows a negative quadratic effect of growth on education. Then, addition to the significant improvement, such an inverse U-shaped effect (Figure 2), is interesting to analyze.

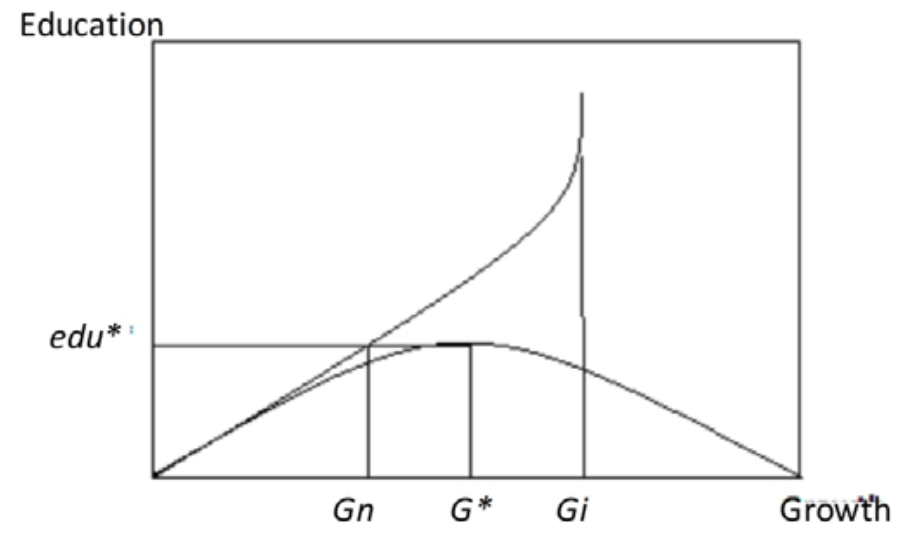

Figure 2: Real and expected effect of growth on the level of education (source: own elaboration)

Figure 2 shows a slightly positive economic growth effect at the onset, which led to slight decrease in illiteracy levels. However, without reaching the expected levels of literacy (see curve increasing in Figure 2). Therefore, it is advisable to consider other factors that take a significant impact on education (see theorem). In this case, the poverty index and the level of corruption, which caused education to return to its low initial levels (see part 2 of the Figure 2 and equation 4).

In addition, in Figure 2, with a $G^{*}$ value, the maximum education value $\left(e d u^{*}\right)$ can be reached, a value that could be reached with a smaller Gn value. Thus, economically, there is a social loss with value, $G^{*}-G n$. In addition to this, if $G i$ is considered as the maximum possible investment with which an optimal level of education is obtained, our model shows that this $G i$ value is inefficient, since education begins falling much earlier. This justifies the fact that it is necessary to attack other social problems that could be significant for increasing the level of education.

The analysis and previous conclusions regarding the nonsignificance and negative effect of the economic growth (final part of Figure 2), make us wonder, what would have these countries done to advance in education, if the economic growth is not a factor? Therefore, it would be interesting to do an economic decomposition to make the analysis more detailed. We analyze the economic decomposition in the next section.

\section{Differences between rich and poor countries}

In order to do the decomposition between countries, we must define a threshold that separates rich countries from the poor one. We observed that countries with a population at the poverty line greater than $3 \%$ had different effects than those with a lower percentage. This level is the goal of the World Bank (2016) to reduce the population living in extreme poverty by 2030. Thus, we can divide our database into two groups:

1. Rich countries: with a percentage of people living with USD 1.90 per day less than $3 \%$,

2. Poor countries: with a percentage of people living with USD 1.90 per day greater than $3 \%$.

For the group of rich countries, we have a total of 48 observations, whereas we have a total of 80 observations in case of poor countries. We use model (4) for the analysis of both groups. In case of the rich countries, we get the following result,

$$
\begin{gathered}
\hat{Y}_{i}=97.197-0.00089 X_{1 i}{ }^{2}+0.027 X_{2 i}-23.05 X_{5 i} \\
t=\quad(-0.19) \quad(1.59) \quad(-3.32), \\
R^{2}=0.3284
\end{gathered}
$$

whereas, in case of the poor countries, we get the following result

$$
\begin{gathered}
\widehat{Y}_{i}=80.233-0.0656 X_{1 i}{ }^{2}+0.2431 X_{2 i}-0.8264 X_{5 i} \\
=(-1.64)(2.62)(-4.16), \\
R^{2}=0.3391
\end{gathered}
$$

We can see that the effect of the growth on inverse U-shaped recovers significance in poor countries and completely lost in rich countries. Likewise, corruption $\left(X_{2}\right)$ loses significance in the group of rich countries, whereas and the significant effect is maintained in the group of poor countries. Finally, the effect of poverty is more marked in rich countries than in poor countries, and remains as the only factor affecting education. Accordingly, the results suggest that the rich countries first eradicated the poverty, which was the determining factor to raise the level of education. Then, before giving a conclusion for the poor countries, we must make additional analysis. 


\section{Econometric analysis in case of poor countries}

First, let's estimate the impact on education only using social factors, poverty and corruption, which we will call reduced model.

$$
Y_{i}=\beta_{0}+\beta_{2} X_{2 i}+\beta_{5} X_{5 i}+u_{i}
$$

Whose estimation is as follows,

$$
\begin{gathered}
\widehat{Y}_{i}=80.233+0.2431 X_{2 i}-0.8264 X_{5 i} \\
t=\quad(2.74) \quad(-4.25), \\
R_{R}^{2}=0.3158
\end{gathered}
$$

Where $R_{R}^{2}$ is the value $\mathrm{R}$ squared referred at the reduced model. We observed that the corruption and poverty remain significate, and with the correct sign.

Further, we aggregated to (6) the variable of the growth, under the transformation $X_{1 i}{ }^{2}$, to obtain our augmented model,

$$
Y_{i}=\beta_{0}+\beta_{1} X_{1 i}^{2}+\beta_{2} X_{2 i}+\beta_{5} X_{5 i}+u_{i}
$$

And the estimation is the showed in (6), this is,

$$
\begin{gathered}
\widehat{Y}_{i}=80.233-0.0656 X_{1 i}{ }^{2}+0.2431 X_{2 i}-0.8264 X_{5 i} \\
t=(-1.64) \quad(2.62) \quad(-4.16), \\
R_{C}^{2}=0.3391
\end{gathered}
$$

Where $R_{C}^{2}$ is the value $\mathrm{R}$ squared referred at the augmented model,

Then, to justify if the aggregation of the growth is significant, we test the following hypothesis,

$$
H_{0}: \beta_{1}=0 \quad \text { vs } \quad H_{a}: \beta_{1} \neq 0,
$$

To reject $H_{0}$ it is necessary that squared sum of residuals of augmented model $\left(\operatorname{RSSA}_{(C)}\right)$ is smaller than squared sum of residuals of the reduced model $\left(\operatorname{RSSA}_{(R)}\right)$, whose statistic is,

$$
F_{o b s}=\frac{\operatorname{RSSA}_{(\mathrm{R})}-\operatorname{RSSA}_{(\mathrm{C})} /(k-g)}{\mathrm{RSSA}_{(\mathrm{C})} /(n-k-1)}
$$

That follow a F-Distribution, this is $F_{n-g-1}^{k-g}$, where $k$ is the number of variables explicative in the augmented model, and $g$ is the number of variables explicative in the reduced model. Thus, $k-g$ is the number of variables aggregate (Gujarati, 2003). This, statistics can be expressed as

$$
F_{o b s}=\frac{R_{C}^{2}-R_{R}^{2} /(k-g)}{\left(1-R_{C}^{2}\right) /(n-g-1)} \sim F_{n-g-1}^{k-g}
$$

So, if $F_{o b s}>F_{n-g-1}^{k-g}$, then we reject $H_{0}$ and, thus, justify that the aggregation is statistically significant.

In our analysis with (6) and (7) we get,

$$
F_{o b s}=\frac{0.3391-0.3158 /(1)}{(1-0.3391) /(76)}=2.67
$$

And $F_{76,05}^{1}=3.96$. Then, the aggregation of the growth is not significant, even though that the aggregation is individually significant in $90 \%$ level (see 6 ).

As a result, statistically our best model is only (6) and, the economic effect is not relevant over the education in $95 \%$.
However, with a base in the p-value this aggregation is nearly significate at $90 \%$, this is, $P\left(F_{76}^{1}>2.67\right)=0.8942$, that seems to be reasonable.

Therefore, we can consider two main results of the analysis:

Result 1. The quadratic effect of the growth on the educational level in rich countries loses significance reached in (4), as well as the level of corruption. The poverty rate remains significant and effective (-23.05). Then, it is advisable that the rich countries add all their efforts to combat poverty, which would be reflected in an immediate effect on educational rates. Combating poverty will have an effect of the 23.05 percent on the literacy rate for each index recovered in poverty reduction.

The $\mathrm{R}$ squared value of the models ranged from 0.33 to 0.45 ; although they are not high values, we can accept them as valid when considering the level of significance of the included variables and take into account that not all functions are linear.

Result 2. If we choose to accept the aggregation of growth as meaningful, then we have a more complete model for the group of the poor countries. This allows us to observe that in addition to the negative effect of the level of growth, there are other variables to consider, corruption and poverty.

In this result, it is worth mentioning that the quadratic and negative effect of growth on the level of education is very low $(-0.0656)$ (see 5 or 7$)$, then the relationship between education and growth follows a form in Figure 2.

\section{Discussion}

Previous research measuring the correlation between education and poverty can be found at three levels: a) micro level (individual), has carried out case studies, mainly showing the effects of poverty/corruption in the education results of persons or individual performance tests such as PISA or competency assessments (Aiyar, Kapur and Mukherjee, 2011; Hallak and Posisson, 2007); b) meso level (contexts), its object of study are families, communities or schools (Dreze and Sen, 2002; Koirala and Aryal, 2005); c) macro level (structural), reviews the effects of the poverty/corruption variables considering national or subnational statistics and trying to explain, in a structural way, the behavior of these from inequalities or imbalances (Mauro, 1995; Bardhan, 1997; Pritchett, 2001; Tanzi and Davoodi, 2001; Dridi, 2014). At this level we place the present study.

The relationship between education and economic growth can be seen from different perspectives. In economics the dominant form is to take education as an independent variable from which influences growth, such as the Mankiw, Romer and Weil (1992) model, that is an adaptation of Solow's model (1956):

$$
Y_{(t)}=K_{(t)}^{\propto} H_{(t)}^{\beta}\left(A_{(t)} L_{(t)}\right)^{1-\alpha-\beta}
$$

Where $H$ (human capital) is determinant of $Y$ (economic growth). Human capital is understood as the workforce formed and endowed with the skills and abilities to better perform a job, that is, education affects growth through the process of training human resources. In this regard, should be noted the results of Hanushek and Kimko (2000), who found a significant positive relationship between the level of science and mathematics of the labor force and the variations in economic growth between countries.

However, we find in the research that there is no significant correlation between both variables, it could even be seen that it becomes negative by showing an inverted U-shape (Figure 2). This micro-macro contradiction was also presented by Pritchett (2001) who compared the growth of educational 
capital and Gross Domestic Product (GDP) growth per worker. The correlation resulted to be insignificant and negative. In attempting to explain the results, Prichett suggested that the low impact between the two variables is due to the fact that the educational capital that the workers have developed could be used in unproductive, but remunerative activities such as piracy and corruption.

Corruption, however, does not appear to be a problem for rich countries with the same intensity as it is for poor countries. Bardhan (1997) points out that corruption is "pervasive and endemic" in developing countries. In this regard, Mauro (1995) showed negative correlations between the Corruption Perception Index and the GDP investment rate. Easterly (2001) also found a negative correlation between corruption and growth, while showing that corruption tends to decrease as the level of development of a country increases. Laffont (2006) concludes with similar conclusions as he places an inverted $U$ between GDP per capita and corruption. As a result, at a certain point of development corruption begins to decline.

Considering the above, we have taken education as a dependent variable in this article, from the possibility of reversing the roles under Myrdal's Cumulative Circular Causation theory (Myrdal, 1957). From this approach, our results coincide with those previously mentioned, economic growth and education have a negative and insignificant correlation. However, by including in the model variables previously considered exogenous, such as corruption and poverty, economic growth and education become significant.

This can be explained by the fact that according to Tanzi and Davoodi (1997) and Mauro (1995), corrupted countries tend to spend less on education. Corrupted countries allocate resources to other areas where it would be easier to get bribes. The results of Dridi (2014) suggest that corruption significantly reduces access to school, is a burden of poor countries that prevents them from accumulating human capital and condemns them to poverty.

We argue that corruption, as a result of the economic situation of low growth, poverty and low educational level, affects education in a Cumulative Circular Causation. Thus, that its effects become more powerful, even above economic variables. Since, even if the educational level were increased, the efforts could be dispersed towards less productive, but more profitable activities (Bardhan, 1997). For example, a student in a more corrupted country would be more attracted for choosing a law degree rather than an engineering degree because it could result in higher incomes (Tanzi and Davoodi, 2001).

These cumulative effects can also be explored with the poverty variable. UNESCO (2006) shows a significant negative correlation between poverty and education, finding that where poverty rates are high, literacy rates tend to be lower. In addition, they considered education as an independent variable. Similarly, if poverty is measured by the level of consumption, Dreze and Sen (2002) showed a significant positive correlation with education at the subnational level of India, where again education was the independent variable.

Studies that have seen education (measured as a percentage of illiteracy) as a dependent variable, have found strong correlations with variables gender, age, household size, residence status in urban areas, formal level of schooling, wealth of home (CarrHill, 2005). On the other hand, Koirala and Aryal (2005) found an illiteracy trap in which minority groups fall from discrimination. The authors' argument indicates that marginalized groups are ignored in official statistics. Therefore, they are not served, they receive few educational opportunities and being illiterate remain marginalized.

We generalize these types of traps as a structural problem of poor economies where the slope of the correlation curve between education and poverty is negative in rich countries, whereas in poor countries the slope of the curve makes it an almost horizontal line. Thus. any effect on the independent variable becomes imperceptible in the dependent (Figure 3). This change in slope is explained by the effects of Cumulative Circular Causation (Figure 4) that the developing countries have experienced and which makes it necessary to address social problems as a whole to obtain a greater impact than to exclusively focus on economic variables.

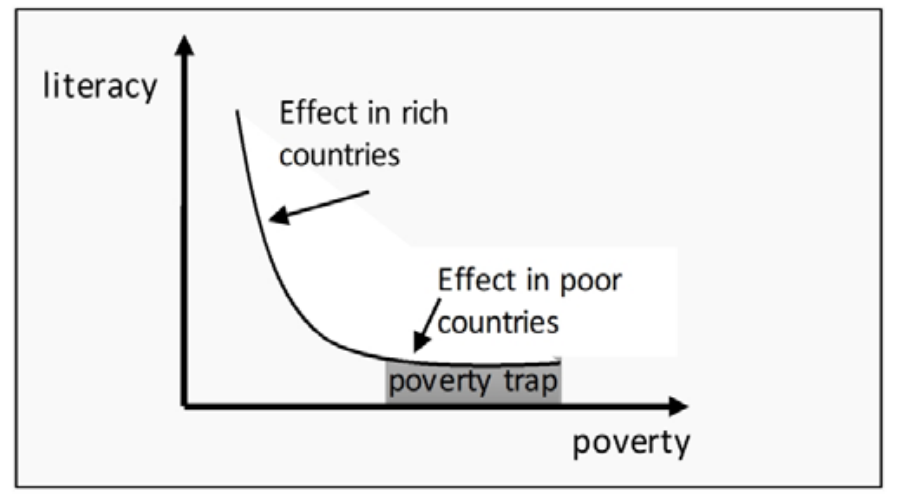

Figure 3: Poverty trap for the poor countries (source: own elaboration)

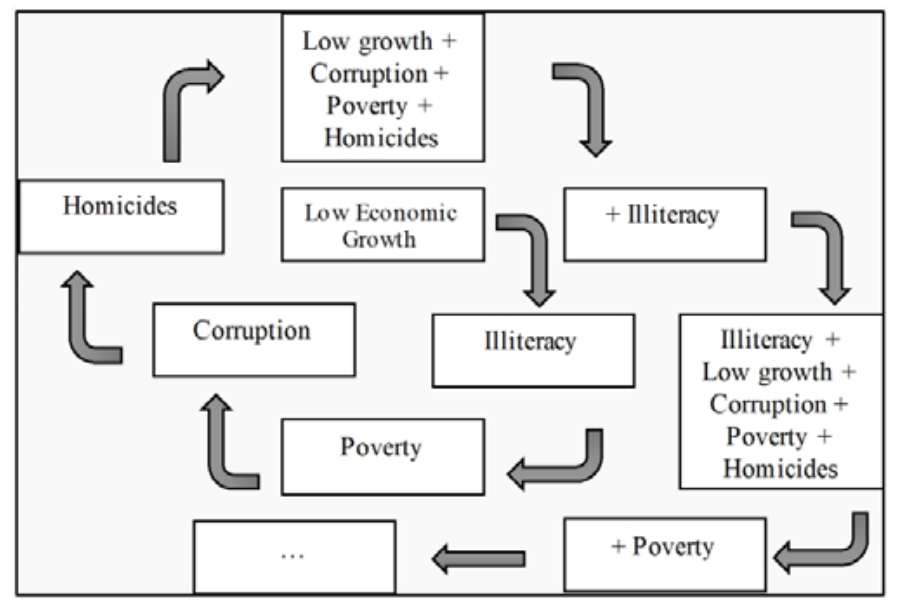

Figure 4: The problem of education under causation circular cumulative (source: own elaboration)

\section{Conclusion}

The relationship between poverty and economy is very complex and has been studied from different points of view. Most of the time the studies consider education as an independent variable. In this article, we proposed to break the dependent-independent dichotomy, to see education at the same time as cause and effect. Supported by Myrdal's theory (Myrdal, 1957), we proposed an econometric model that measured the correlation between economic growth and education. The results showed that we should include other variables into the model to gain significance of variables, we proposed corruption and poverty.

Furthermore, we separated the measurement of the effects between rich and poor countries to analyze differences between both groups. This separation enabled us to prove the effects of a Cumulative Circular Causation for poor countries. Therefore, low growth leads to high rates of illiteracy, higher illiteracy means higher rates of poverty, an environment of poverty leads to other problems such as increased violence and corruption, 
high rates of violence and corruption increase educational lags and decrease possibilities of schooling, and, thus, a high illiteracy rate.

By cumulative effects, the first independent variable (economic growth) has decreased its incidence effects on the dependent variable that now affects the effects of the causal variables, before effect of the first one (Figure 4), which would mean a variation in the slope. The change of sign is explained by considering that at a given level of growth, economic growth not only fails to positively influence literacy, but also has a negative effect because of the greater effects that the rest of the variables have. Therefore, even if countries continue to grow, education stagnates or decreases, which ends up slowing down the growth. Therefore, neither an increasing rate of growth can lead to lower illiteracy, nor increasing literacy can increase a growth. As a result, countries fall into a poverty trap in which they reproduce intergenerationally poverty and illiteracy (Figure 3 ). This type of studies allows visualizing the variables with greater effects on a given situation. So, we suggest that each country should consider its conditions in a structural way and not in isolation. We propose that state intervention in poor countries should address social variables, while in developed countries their weak point is to ensure that the percentage of their population in the poverty line does not increase beyond $3 \%$, that we identified as the threshold of the poverty trap.

\section{Acknowledgements}

The authors wish to acknowledgements the support of Universidad La Salle México for its financial support, which was carried out under the projects (CA-015/14): Mathematical Modeling of Various Economic Phenomena and (SAD-10/17): Strategies of innovation and permanence of informal bussines organizations.

\section{References}

Aiyar, Y., Kapur, A., Mukherjee, A. (2011) "PISA 2010: Unpacking India's Education Budget", Annual Status of Education Report (Rural) 2010, pp. 11-12. Mumbai: Pratham Resource Center.

Arellano, M., Bond, S. (1991) 'Some Tests of Specification for Panel Data: Monte Carlo Evidence and an Application to Employment Equations', Review of Economic Studies, vol. 58, no. 2, pp. 277-297. https://doi.org/ 10.2307/2297968

Bardhan, P. (1997) 'Corruption and Development: A Review of Issues', Journal of Economic Literature, vol. 35, no. 3, pp. 1320-1346.

Barro, R.J. (1991) 'Economic Growth in a Cross Section of Countries', The Quarterly Journal of Economics, vol. 106, no. 2, pp. 407-443. https://doi.org/10.2307/2937943

Bonilla, C.S. (2013) 'Educación y crecimiento económico entre 1975 y 2005. Una aplicación del modelo de datos del panel dinámico de Arellano y Bond', Revista Sociedad y Economía, No. 25, pp. 255-276.

Bruner, J. (1997) La educación puerta de la cultura, Colección Aprendizaje No. 125. Madrid: Visor.

Carr-Hill, R. (2005) Assessment of international literacy and numeracy data (Phase II), Background paper for EFA Global Monitoring Report 2006.

Cipolla, C. (1969) Literacy and Development in the West, Harmondsworth, Penguin Books.

Dreze, J., Sen, A. (2002) India: Development and Participation, New York: Oxford University Press.

Dridi, M. (2014) 'Corruption and Education: Empirical evidence', International Journal of Economics and Financial, vol. 4, no. 3, pp. 476-493.

Easterly, W. (2001) The Elusive Quest for Growth, Cambridge: The MIT Press, 2001.

Freire, P. (1970) Pedagogía del oprimido, México: Siglo XXI. Gujarati, D. (2003) Econometria, México: McGraw-Hill.

Hallak, J., Poisson, M. (2007) Corrupt schools, corrupt universities: What can be done? Paris: International Institute for Educational Planning.

Hanushek, E.A., Kimko, D.D. (2000) 'Schooling, Labor Force Quality, and the Growth of Nations', American Economic Review, vol. 90, no. 5, pp. 1184-1208. https://doi.org/10.1257/ aer.90.5.1184

IMF (2017) International Monetary Fund, data sites, [Online], Available: http://data.imf.org/ [10 Jun 2017].

Koirala, B.N., Aryal, B.R. (2005) Options for policy and practice in Nepal, Background paper for EFA Global Monitoring Report 2006.

Laffont, J.J. (2006) "Corruption and Development", Understanding Poverty, in Banerjee, A.V., Bénabou, R. and Mookherjee, D. (eds), Understanding Poverty, New York: Oxford University Press.

Mankiw, G.N., Romer, D., Weil, D.N. (1992) 'A Contribution to the Empirics of Economic Growth', The Quarterly Journal of Economics, vol. 107, no. 2, pp. 407-437. https://doi. org/10.2307/2118477

Mauro, P. (1995) 'Corruption and Growth', The Quarterly Journal of Economics, vol. 110, no. 3, pp. 681-712. https://doi. org/10.2307/2946696

Myrdal, G. (1944) An American Dilemma, The negro problem and modern democracy, EUA: Harper \& Row.

Myrdal, G. (1957) Economic theory and under-developed regions, Londres: Gerald Duckworth \& Co.

Nurkse, R. (1953) Problems of Capital Formation in Underdeveloped Countries, New York: Oxford Univ. Press.

Pritchett, L. (2001) 'Where Has All the Education Gone?', The World Bank Economic Review, vol. 15, no. 3, pp. 367-391. https://doi.org/10.1093/wber/15.3.367

Romer, P.M. (1986) 'Increasing Returns and Long-Run Growth', Journal of Political Economy, vol. 94, no. 5, pp. 1002-1037. https://doi.org/10.1086/261420

Rostow, W.W. (1960) The Stages of Economic Growth: A NonCommunist Manifesto, Cambridge, UK, Cambridge University Press.

Sauvageot, C. (1978) The Relationship between School Enrolment Variables and the Subsequent Educational Attainment of the Age-Group, in: UNESCO Towards a Methodology for Projecting Rates of Literacy and Educational Attainment. Paris: UNESCO.

Solow, R. M. (1956) 'A Contribution to the Theory of Economic Growth', The Quarterly Journal of Economics, vol. 70, no. 1, pp. 65- 94. https://doi.org/10.2307/1884513

Tanzi, V., Davoodi, H.R. (1997) Corruption, Public Investment, and Growth, IMF Working Paper, WP/97/139.

Tanzi, V., Davoodi, H.R. (2001) Corruption, Growth, and Public Finances, in A.K. Jain (Ed.), The Political Economy of Corruption, chapter 5, pp. 90-110, London: Routledge.

Transparency International (2016) Corruption Perception Index. [Online], Available: http://www.transparency.org/research/cpi/ [30 Jun 2017].

UNESCO (1957) World Illiteracy at Mid-Century, Paris: UNESCO.

UNESCO (1958) Recommendation concerning the International 
Standardization of Educational Statistics. Paris: UNESCO.

UNESCO (1995) Compendium of statistics on illiteracy, No. 35, Paris: UNESCO.

UNESCO (2006) Education for all. Literacy for life. Global monitoring report 2006, Paris: UNESCO.

UNESCO (2014) UNESCO Institute for Statics, [Online], Available: http://on.unesco.org/literacy-map [10 Jun 2017].

World Bank (2016) Taking on Inequality. Poverty and shared prosperity 2016, Washington, DC: World Bank.

World Bank (2017a) Atlas of Sustainable Development Goals 2017: From World Development Indicators. World Bank Atlas; Washington, DC: World Bank.

World Bank (2017b) Monitoring Global Poverty. Report of the Commission on global poverty, Washington, DC: World Bank 